\title{
Association between cancer prevalence and use of thiazolidinediones: results from the Vermont Diabetes Information System
}

\author{
Maria E Ramos-Nino* ${ }^{* 1}$, Charles D MacLean ${ }^{\dagger 2}$ and Benjamin Littenberg ${ }^{\dagger 2,3}$
}

\author{
Address: ${ }^{1}$ University of Vermont, Department of Pathology, Vermont 05405, USA, ${ }^{2}$ University of Vermont, Department of Medicine, Vermont \\ 05401, USA and ${ }^{3}$ University of Vermont, College of Nursing and Health Sciences, Burlington, Vermont 05401, USA \\ Email: Maria E Ramos-Nino* - Maria.Ramos@uvm.edu; Charles D MacLean - Charles.Maclean@vtmednet.org; \\ Benjamin Littenberg - Benjamin.Littenberg@vtmednet.org \\ * Corresponding author †Equal contributors
}

Published: 21 June 2007

BMC Medicine 2007, 5:17 doi:10.1186/1741-70/5-5-17
Received: 4 November 2006

Accepted: 21 June 2007

This article is available from: http://www.biomedcentral.com/174I-7015/5/17

(c) 2007 Ramos-Nino et al; licensee BioMed Central Ltd.

This is an Open Access article distributed under the terms of the Creative Commons Attribution License (http://creativecommons.org/licenses/by/2.0), which permits unrestricted use, distribution, and reproduction in any medium, provided the original work is properly cited.

\begin{abstract}
Background: Peroxisome proliferator-activated receptors (PPARs) have emerged as important drug targets for diabetes. Drugs that activate PPAR $\gamma$, such as the thiazolidinediones (TZDs), are widely used for treatment of Type 2 diabetes mellitus. PPAR $\gamma$ signaling could also play an antineoplastic role in several in vitro models, although conflicting results are reported from in vivo models. The effects of TZDs on cancer risk in humans needs to be resolved as these drugs are prescribed for long periods of time in patients with diabetes.

Methods: A total of 1003 subjects in community practice settings were interviewed at home at the time of enrolment into the Vermont Diabetes Information System, a clinical decision support program. Patients self-reported their personal and clinical characteristics, including any history of malignancy. Laboratory data were obtained directly from the clinical laboratory and current medications were obtained by direct observation of medication containers. We performed a crosssectional analysis of the interviewed subjects to assess a possible association between cancer diagnosis and the use of TZDs.

Results: In a multivariate logistic regression model, a diagnosis of cancer was significantly associated with TZD use, even after correcting for potential confounders including other oral antidiabetic agents (sulfonylureas and biguanides), age, glycosylated hemoglobin AIC, body mass index, cigarette smoking, high comorbidity, and number of prescription medications (odds ratio $=1.59, \mathrm{P}$ $=0.04)$. This association was particularly strong among patients using rosiglitazone $(O R=1.89, P$ $=0.02)$, and among women $(O R=2.07, P=0.01)$.
\end{abstract}

Conclusion: These data suggest an association between TZD use and cancer in patients with diabetes. Further studies are required to determine if this association is causal.

\section{Background}

Factors affecting cancer incidence in the diabetic population are diverse and complex. Diabetes is a risk factor for colon, pancreas, breast, endometrium and liver cancer in women. In men, although diabetes it is a risk factor for bladder cancer $[1,2]$, it is a protective factor for prostate 
cancer [3], particularly in those receiving anti-diabetic treatment $[4,5]$. One of the limitations of such observational studies is that most have not examined the potential association between medication use and cancer risk.

The increasing prevalence of diabetes has intensified the search for new therapies. Orally administered anti-diabetic agents (oral agents) can be used alone or in combination with other oral agents or insulin [6]. Over the last decade, the gamma subtype of the peroxisome proliferator-activated receptors (PPAR $\gamma$ ), has emerged as an important drug target in diabetes [7]. PPAR $\gamma$ agonists currently used as oral agents are thiazolidinedione (TZD) drugs, including rosiglitazone and pioglitazone.

The TZDs are attractive options in the therapy of diabetes because they decrease insulin resistance [8-10]. In addition to being a therapeutic option in diabetes, PPAR $\gamma$ agonists are now believed to be a potential strategy for treatment of several cancers $[11,12]$. Although differential expression of PPAR $\gamma$ is observed in tumors compared to normal tissues, and PPAR $\gamma$ agonists have been shown to inhibit tumor cell growth and survival, the interdependence of these observations is unclear. Conflicting results on the pro-carcinogenic and anti-tumorigenic role of PPAR $\gamma$ agonists such as the TZDs can be found in the literature. Some of the anti-tumorigenic effects of TZDs have been demonstrated in colon cancer cells [13], glioma cells in vivo [14], lung cancer cells $[15,16]$, thyroid carcinoma cells [17], hepatocellular carcinoma [18] and others. However, some studies have shown pro-carcinogenic roles for TZDs. Saez et al showed that the use of a TZD increased the number of polyps in the colon of mice [19]. Seargent, Yates and Gill [20] demonstrated that the PPAR $\gamma$ antagonist GW9662 inhibited growth of human mammary tumor cell lines. Surprisingly, GW9662 prevented rosiglitazone-mediated PPAR $\gamma$ activation, but enhanced rosiglitazone-induced growth inhibition [20]. As such, these data support the existence of PPAR $\gamma$-independent pathways and challenge the belief that TZDs mediate their effects only via activation of PPAR $\gamma$. These conflicting results must be resolved, as the possible pro-carcinogenic effects of TZDs raise questions about their long-term safety in patients.

Evidence of both pro-carcinogenic and anti-tumorigenic effects of PPAR $\gamma$ agonists have been mainly studied in vitro and in vivo models that do not take into full account the metabolic characteristics of patients with diabetes. Recently, a population-based report showed that TZDs were associated with reduced risk of lung cancer in diabetic patients [21] in agreement with previous in vitro studies $[15,16]$. Here, we report the association between anti-diabetic therapies, particularly TZDs, and cancer prevalence in diabetic patients participating in the Vermont Diabetes Information System (VDIS).

\section{Methods}

This study is part of a larger project, the Vermont Diabetes Information System (VDIS), a study of 8855 adults with diabetes in primary care practices [22]. The subjects comprised all diabetic adults in 69 practices in Vermont and adjacent New Hampshire and New York. A field survey was completed at study baseline with a sub-sample of subjects in order to provide a better understanding of the non-laboratory features of diabetes. Patients' names were randomly sorted and patients contacted by telephone until a sample of approximately $15 \%$ of patients from each practice agreed to participate in the field survey to give a sample of 1007 at the time of analysis. Four patients were dropped from the analysis due to incomplete information, leaving a final sample of 1003 .

Subjects completed a questionnaire at home and then were visited by a trained research assistant who reviewed the questionnaire responses, assisted the subject with any missing or unacceptable responses, reviewed the subject's medications, and measured their height and weight using a portable stadiometer and scale. Race, education, income, marital status, functional status, smoking, alcohol consumption and comorbid conditions were obtained by questionnaire. Prior to the interview, patients were instructed to gather all current medications, including over the counter preparations, for review by the research assistant. The medication list was ascertained by direct observation of the medication container with recording of the drug name, dose, frequency and route of administration. Duration of therapy was not recorded.

We used the SF-12 health survey to determine physical and mental functional status. Results were scored and normalized using designed algorithms and expressed in terms of the Physical Component Summary (PCS) and the Mental Component Summary (MCS) [23]. To determine comorbidity, we used a modification of the Self-Administered Comorbidity Questionnaire [24] in which we asked each patient to indicate whether they have had the following conditions: heart attack, heart failure, peripheral arterial disease, stroke, dementia, chronic obstructive lung disease, rheumatic disease, peptic ulcer, cirrhosis, paralysis, renal insufficiency, diabetic vascular complications, AIDS/HIV and depression. All patients also had diabetes, which was not included in the comorbidity count. Patients with two or more comorbid conditions were considered "high comorbidity". Patients were classified as having cancer if they reported any cancer, leukemia, or lymphoma. Specific cancer sites and dates of diagnosis were not recorded. 
The interviews occurred between July 2003 and March 2005. Most laboratory data were obtained from the patients' local clinical laboratories, which all use the same Diabetes Control and Complications Trial/Epidemiology of Diabetes Interventions and Complications high performance, liquid chromatography (HPLC) method for the determination of glycosylated hemoglobin (A1C). Less than $1 \%$ of A1C tests were performed using the Bayer DCA 2000 immunoassay point of care instrument, which has been shown to compare favorably with the HPLC method [25].

The research protocol was carried out in compliance with the Helsinki Declaration and was approved by the Committee on Human Research of the University of Vermont. The interviewed subjects provided written informed consent. The full study protocol and variables and the medication profiles of the subjects have been previously reported $[22,26]$.

\section{Statistical approach}

We performed a cross-sectional analysis of the interviewed subjects at the time of their enrollment in the VDIS trial. We explored the association between cancer and the use of oral agents, using logistic regression with history of cancer as the outcome variable and the use of TZDs as the primary predictor variable. We then adjusted for possible confounding by social and clinical factors. Potential confounders tested were: other oral anti-diabetic agents (sulfonylureas and biguanides; yes/no), gender, age (years), race (white/other), glycosylated hemoglobin level (A1C; mg \%), insulin use (yes/no), body mass index (BMI; kg/ $\mathrm{m}^{2}$ ), alcohol drinking (yes/no), cigarette smoking (yes/ no), income (in eight ordered categories), duration of diabetes in years, high comorbidity (two or more comorbid conditions), number of prescription medications, number of anti-diabetic drugs, physical function status and mental function status. To reduce the number of variables in the final model, we excluded potential confounders that were associated with the outcome in univariate analyses with $P>0.2$. Such weak association argues that the variable is unlikely to be a confounder. However, variables representing use of TZDs, sulfonylureas and biguanides were included regardless of their $P$ values. Because diabetes is associated with an increased incidence of breast and endometrial cancers and a reduced incidence of prostate cancers [2-4], we also performed separate multivariate analyses for men and women. Because the effects of TZDs on cancer might be mediated through pathways other than PPAR $\gamma$, and therefore not be an effect of all TZDs, we also performed separate analyses for pioglitazone and rosiglitazone. We used Stata/SE v.9.2 (StataCorp, College Station, TX, USA) for all analyses.

\section{Results}

The general characteristics of the study population are described in Table 1 . The study population is representative of adults with diabetes in primary care practices in Northern New England, USA. Because many of the subjects are over retirement age or suffer disability from chronic conditions, their income is lower than healthy younger Americans.

The number of cancer patients in this population was 126 (12.6\%). A total of $26 \%$ of the subjects used a TZD, including $13.6 \%$ on pioglitazone and $12.8 \%$ on rosiglitazone (Table 1).

Table 2 presents univariate associations between cancer diagnosis and the other study variables. Rosiglitazone, age, high comorbidity, and number of prescription medications were significantly associated with cancer prevalence.

Next, potential confounding variables associated with cancer with $P<0.2$ and all oral agents regardless of their $P$-value were included in a logistic regression model using cancer as the outcome. These included TZD therapy, sulfonylurea therapy, biguanide therapy, age, glycosylated hemoglobin (A1C), BMI $\left(\mathrm{kg} / \mathrm{m}^{2}\right)$, cigarette smoking, high

Table I: Baseline characteristics of 1003 adults with diabetes

\begin{tabular}{lc}
\hline Characteristic & $\mathrm{n}(\%)$ or mean (sd) \\
\hline History of cancer & $126(12.6 \%)$ \\
TZD therapy & $263(26.2 \%)$ \\
$\quad$ Pioglitazone & $136(51.3 \%)$ \\
$\quad$ Rosiglitazone & $128(48.7 \%)$ \\
$\quad$ Any TZD alone & $-71(27.0 \%)$ \\
$\quad$ TZD and biguanide & $-65(24.7 \%)$ \\
$\quad$ TZD and sulfonylurea & $-56(21.3 \%)$ \\
TZD and biguanide and sulfonylurea & $-71(27.0 \%)$ \\
Gender: & \\
$\quad$ Men & $457(45.6 \%)$ \\
Women & $546(54.4 \%)$ \\
Age, years & $64.8(12.0)$ \\
White ethnicity & $973(97.3 \%)$ \\
Glycosolated hemoglobin AIC, \% & $7.13(1.3)$ \\
Insulin use & $185(18.4 \%)$ \\
Body mass index, kg/m ${ }^{2}$ & $33.81(7.4)$ \\
Alcohol use & $274(27.4 \%)$ \\
Cigarette smoking & $170(16.9 \%)$ \\
Median annual income, \$ & $15000-29999$ \\
Duration of diabetes, years & $10.2(10.3)$ \\
High comorbidity & $495(49.4 \%)$ \\
Number of prescription medications & $6.7(3.8)$ \\
Number of anti-diabetic medications & $1.2(0.9)$ \\
Physical functional status & $41.2(12.4)$ \\
Mental functional status & $50.0(10.7)$ \\
& \\
\hline
\end{tabular}

TZD, thiazolidinedione; sd, standard deviation; $\mathrm{n}$, number of subjects with the characteristic. 
Table 2: Univariate associations between cancer and other patient characteristics

\begin{tabular}{|c|c|c|c|c|c|c|}
\hline \multirow[t]{2}{*}{ Characteristic } & \multicolumn{2}{|c|}{ Cancer patients } & \multicolumn{2}{|c|}{ Non-cancer patients } & \multirow[t]{2}{*}{ Odds ratio } & \multirow[t]{2}{*}{$P$} \\
\hline & $\%$ or mean $(s d)$ & $\mathrm{n}$ & $\%$ or mean $(s d)$ & $\mathrm{n}$ & & \\
\hline Number of subjects & & 126 & & 877 & & \\
\hline TZD therapy & $32.5 \%$ & 126 & $25.3 \%$ & 877 & 1.42 & 0.09 \\
\hline Pioglitazone & $13.5 \%$ & 126 & $13.6 \%$ & 877 & 0.99 & 0.98 \\
\hline Rosiglitazone & $19.1 \%$ & 126 & $11.9 \%$ & 877 & 1.75 & 0.03 \\
\hline Sulfonylurea therapy & $34.9 \%$ & 126 & $38.2 \%$ & 877 & 0.87 & 0.48 \\
\hline Biguanide therapy & $39.7 \%$ & 126 & $40.0 \%$ & 877 & 0.99 & 0.94 \\
\hline Nateglinide therapy & $0.8 \%$ & 126 & $0.5 \%$ & 877 & 1.75 & 0.62 \\
\hline Men & $42.1 \%$ & 126 & $46.1 \%$ & 877 & 0.85 & 0.40 \\
\hline Age, years & $69.1(10.2)$ & 126 & $64.2(12.1)$ & 877 & 1.04 & $<0.001$ \\
\hline White ethnicity & $97.6 \%$ & 125 & $97.3 \%$ & 875 & 1.15 & 0.83 \\
\hline AIC, mean \% & $7.0(1.3)$ & 126 & $7.2(1.3)$ & 871 & 0.88 & 0.12 \\
\hline Insulin therapy & $15.9 \%$ & 126 & $18.8 \%$ & 877 & 0.81 & 0.43 \\
\hline Body mass index, $\mathrm{kg} / \mathrm{m}^{2}$ & $32.7(6.8)$ & 125 & $34.0(7.5)$ & 865 & 0.97 & 0.06 \\
\hline Alcohol drinking & $25.4 \%$ & 126 & $27.6 \%$ & 876 & 0.89 & 0.60 \\
\hline Cigarette smoking & $11.1 \%$ & 126 & $17.8 \%$ & 876 & 0.58 & 0.06 \\
\hline Median annual income, $\$$ & $15000-29999$ & 114 & $15000-29999$ & 813 & 1.02 & 0.75 \\
\hline Duration of diabetes, years & $10.2(9.7)$ & 124 & $10.2(10.4)$ & 829 & 1.00 & 0.98 \\
\hline High comorbidity & $71.4 \%$ & 126 & $46.2 \%$ & 877 & 2.91 & $<0.001$ \\
\hline Number of prescription medications & $7.3(4.3)$ & 126 & $6.6(3.7)$ & 877 & 1.05 & 0.05 \\
\hline Number of anti-diabetic drugs & $1.2(1.0)$ & 126 & I.2(0.9) & 877 & I.0I & 0.92 \\
\hline Physical functional status & $40.9(13.7)$ & 125 & $42.3(12.7)$ & 871 & 0.99 & 0.27 \\
\hline Mental functional status & $50.5(10.5)$ & 126 & $49.4(10.9)$ & 875 & 1.01 & 0.30 \\
\hline
\end{tabular}

sd, standard deviation; $n$, number of patients for which data were available; TZD, thiazolidinedione.

comorbidity conditions, and number of prescription medications. This model showed a significant association between cancer and the use of any TZD $(\mathrm{OR}=1.59,95 \%$ CI (1.03-2.44), $P=0.04$ ) (Table 3). A significant association was found for rosiglitazone $(\mathrm{OR}=1.89,95 \% \mathrm{CI}$ (1.11-3.19), $P=0.02$ ) (Table 3$)$, but not for pioglitazone $(\mathrm{OR}=1.09,95 \%$ CI $(0.62-1.94), P=0.76)$ (Table 3$)$. Other variables significantly associated with cancer history include age and high comorbidity (Table 3 ).

When the analysis was stratified by gender, it showed a highly significant association between cancer prevalence and TZDs in women $(\mathrm{OR}=2.07,95 \% \mathrm{CI}(1.18-3.63), P=$ $0.01)$ (Table 4), but not in men $(\mathrm{OR}=1.20,95 \% \mathrm{CI}$ $(0.58-2.46), P=0.63)$ (Table 4$)$.

TZDs are used alone or in combination with other oral anti-diabetic agents (Table 1). The multivariate analyses found no evidence for the use of other oral agents confounding the relationship of TZD therapy with cancer (Table 3), but in the gender stratified analysis, the use of sulfonylurea is negatively associated with cancer in women $(\mathrm{OR}=0.49,95 \% \mathrm{CI}(0.27-0.89), P=0.02)$ (Table $4)$. Other variables significantly associated with cancer history in women included high comorbidity $(\mathrm{OR}=2.90$, $95 \%$ CI $(1.56-5.41), P=0.001)$ and number of prescription medications $(\mathrm{OR}=1.09,95 \%$ CI $(1.01-1.18), P=$ 0.03 ) (Table 4). Similarly, in men, high comorbidity (OR $=4.29,95 \%$ CI $(2.11-8.72), P<0.001)$ and number of prescription medications $(\mathrm{OR}=0.89,95 \% \mathrm{CI}(0.80-$ $0.98), P=0.02$ ) were associated with cancer history (Table $4)$.

\section{Discussion}

We have demonstrated an association between the use of TZDs and cancer in a community-based population of adults with diabetes. The association was observed primarily among rosiglitazone users and not among subjects using pioglitazone. Furthermore, the association was found in women, but not men.

The gender-dependent observation is difficult to explain. TZDs have gained widespread use in polycystic ovary syndrome (PCOS) [27] that has been correlated with endometrial cancer [28]. Perhaps the TZDs are not causing cancer, but are used by patient with cancers caused by PCOS. It is worth noting that as the average age in this population is post-menopausal, the use of TZDs for PCOS is probably low. Unfortunately, we do not have data on the history of PCOS in these patients. More alarmingly, it is possible that TZDs disrupt estrogen pathways and increase the incidence of hormone-sensitive tumors such as those of the breast and endometrium. We do not know which specific tumors are increased in the TZD users in this population.

Likewise, we are not aware of a convincing explanation or previous results to support the finding in this study of an 
Table 3: Multivariate logistic regression: cancer vs. TZD therapy and potential confounders including combined oral anti-diabetic treatments

\begin{tabular}{|c|c|c|c|}
\hline & Odds ratio & $P$ & $95 \% \mathrm{Cl}$ \\
\hline Any TZD therapy $(\mathrm{N}=983)$ & 1.59 & 0.04 & $1.03-2.44$ \\
\hline Age & 1.03 & 0.01 & $1.01-1.05$ \\
\hline Biguanide therapy & 1.37 & 0.14 & $0.90-2.10$ \\
\hline Sulfonylurea therapy & 0.70 & 0.09 & $0.45-1.05$ \\
\hline Glycosolated hemoglobin AIC, \% & 0.91 & 0.30 & $0.76-1.08$ \\
\hline Body mass index, $\mathrm{kg} / \mathrm{m}^{2}$ & 0.97 & 0.08 & $0.94-1.00$ \\
\hline Cigarette smoking & 0.61 & 0.13 & $0.33-1.15$ \\
\hline High comorbidity conditions & 3.40 & $<0.001$ & $2.14-5.39$ \\
\hline $\begin{array}{l}\text { Number of prescription } \\
\text { medications }\end{array}$ & 1.01 & 0.97 & $0.95-1.07$ \\
\hline $\begin{array}{l}\text { Rosiglitazone therapy ( } N= \\
\text { 983) }\end{array}$ & 1.89 & 0.02 & $1.11-3.19$ \\
\hline Age & 1.03 & 0.05 & $1.01-1.05$ \\
\hline Biguanide therapy & 1.34 & 0.16 & $0.89-2.04$ \\
\hline Sulfonylurea therapy & 0.70 & 0.10 & $0.46-1.07$ \\
\hline Glycosolated hemoglobin AIC, \% & 0.92 & 0.34 & $0.77-1.09$ \\
\hline Body mass index, $\mathrm{kg} / \mathrm{m}^{2}$ & 0.97 & 0.09 & $0.94-1.00$ \\
\hline Cigarette smoking & 0.61 & 0.13 & $0.33-1.15$ \\
\hline High comorbidity conditions & 3.32 & $<0.001$ & $2.10-5.26$ \\
\hline $\begin{array}{l}\text { Number of prescription } \\
\text { medications }\end{array}$ & 1.00 & 0.92 & $0.95-1.06$ \\
\hline $\begin{array}{l}\text { Pioglitazone therapy }(\mathrm{N}= \\
\text { 983) }\end{array}$ & 1.09 & 0.76 & $0.62-1.94$ \\
\hline Age & 1.03 & 0.01 & $1.01-1.05$ \\
\hline Biguanide & $\mathrm{I} .4 \mathrm{I}$ & 0.11 & $0.93-2.13$ \\
\hline Sulfonylureas & 0.71 & 0.12 & $0.47-1.09$ \\
\hline Glycosolated hemoglobin AIC, \% & 0.91 & 0.27 & $0.77-1.08$ \\
\hline Body mass index, $\mathrm{kg} / \mathrm{m}^{2}$ & 0.98 & 0.12 & $0.91-1.01$ \\
\hline Cigarette smoking & 0.62 & 0.13 & $0.33-1.15$ \\
\hline High comorbidity conditions & 3.36 & $<0.001$ & $2.12-5.32$ \\
\hline $\begin{array}{l}\text { Number of prescription } \\
\text { medications }\end{array}$ & 1.01 & 0.81 & $0.95-1.07$ \\
\hline
\end{tabular}

TZD, thiazolidinedione.

association with cancer for rosiglitazone, but not pioglitazone. As both are thought to activate PPAR $\gamma$ with similar potency, this finding suggests another mechanism for the association. Furthermore, we cannot explain the differences found between the anti-cancer effect of PPAR $\gamma$ activation in vitro and our results. Some studies suggest that natural mutant PPAR $\gamma$ alleles might impair native PPAR $\gamma$ function [29] and differences in the PPAR $\gamma$ genotype could modify the response to TZD treatment. Further studies incorporating rigorous controls for genetic and environmental confounders are required to identify the molecular mechanisms involved in the differences found between the two drugs and the discrepancies with in vitro studies.

Cancer patients used slightly more prescription medications than non-cancer patients, but similar numbers of anti-diabetic medications (Table 2). This is consistent
Table 4: Multivariate logistic regression of dependent variable cancer versus any TZD therapy (Rosiglitazone or Pioglitazone) and potential confounders stratified by gender

\begin{tabular}{lccc}
\hline & Odds ratio & $P$ & $95 \% \mathrm{Cl}$ \\
\hline Women (N = 535) & & & \\
TZD therapy & 2.07 & 0.01 & $1.18-3.63$ \\
Age & 1.02 & 0.25 & $0.99-1.04$ \\
Biguanide use & 1.63 & 0.09 & $0.93-2.84$ \\
Sulfonylurea use & 0.49 & 0.02 & $0.27-0.89$ \\
Glycosolated hemoglobin AIC, \% & 0.94 & 0.59 & $0.76-1.17$ \\
Body mass index, kg/m ${ }^{2}$ & 0.97 & 0.07 & $0.93-1.00$ \\
Cigarette smoking & 0.43 & 0.06 & $0.18-1.03$ \\
High comorbidity conditions & 2.90 & 0.001 & $1.56-5.41$ \\
Number of prescription & 1.09 & 0.03 & $1.01-1.18$ \\
medications & & & \\
\hline Men (N = 448) & & & \\
TZD therapy & & & \\
Age & 1.20 & 0.63 & $0.58-2.46$ \\
Biguanide use & 1.05 & 0.01 & $1.01-1.08$ \\
Sulfonylurea use & 0.99 & 0.97 & $0.51-1.91$ \\
Glycosolated hemoglobin AIC, \% & 1.22 & 0.56 & $0.63-2.35$ \\
Body mass index, kg/m ${ }^{2}$ & 0.83 & 0.22 & $0.62-1.12$ \\
Cigarette smoking & 0.97 & 0.32 & $0.91-1.03$ \\
High comorbidity conditions & 0.78 & 0.62 & $0.30-2.03$ \\
Number of prescription & 4.29 & $<0.001$ & $2.11-8.72$ \\
medications & 0.89 & 0.018 & $0.80-0.98$ \\
& & & \\
\hline
\end{tabular}

TZD, thiazolidinedione.

with the need for additional anti-cancer therapies as determined from the prescription drug list of cancer patients compared to non-cancer patients. Cigarette smoking is somewhat less prevalent in the cancer patients than the non-cancer patients, in spite of the well-known association of tobacco use and cancer incidence. This could be because cancer survivors are highly motivated to quit smoking [30], or that smokers with cancer die at a higher rate than non-smokers with cancer [31].

We note that cancer patients tended to have more comorbid conditions than non-cancer patients. This could be due to the well-known associations between some of the specific measured comorbidities and various cancers. For instance, chronic obstructive lung disease and cirrhosis are often associated with lung cancer and hepatoma, respectively $[32,33]$.

To further address potential confounding, we also included two other common oral anti-diabetic agents (sulfonylureas and biguanides). Results presented here showed no significant association of either class of medications with cancer prevalence or any confounding of the association between TZDs and cancer in the general model (Table 3). However, a protective effect of sulfonylurea therapy for women was found in the gender-stratified model (Table 4). The fact that we observe an 
association with cancer for some PPAR $\gamma$ agonists (TZDs), but not others (sulfonylureas; [34]) suggests the notion of PPAR $\gamma$-independent mechanisms in the association between TZDs and cancer.

This study has several strengths. First, the interviewed subjects were a randomly selected subset of a large population of patients receiving care in the Northeast USA, and are therefore likely to be representative of primary care patients. Second, all data on medications were obtained by direct observation in the patient's home and not from secondary sources.

This study does however also have several limitations, including lack of confirmation of the cancer diagnoses, and lack of information on the time relation between onset of cancer and the use of TZDs or the duration of treatment. In addition, information on the type or stage of the cancer cases is missing, and skin cancers are not reported. As in any cross-sectional study, unmeasured confounders could be responsible for the apparent associations found.

\section{Conclusion}

Our findings suggest a possible association between cancer and the use of TZDs, particularly rosiglitazone, and particularly among women, but this association requires further investigation.

\section{Competing interests}

The author(s) declare that they have no competing interests.

\section{Authors' contributions}

All authors contributed equally to this work

\section{Acknowledgements}

This research was supported by NIH grants ROI DK6II67, K24

DK068380 (BL), and NCl grant KOI CA 104I59-0I (MERN).

\section{References}

I. Schiel R, Beltschikow W, Steiner T, Stein G: Diabetes, insulin, and risk of cancer. Methods Find Exp Clin Pharmacol 2006, 28: I69-I75.

2. Khan M, Mori M, Fujino Y, Shibata A, Sakauchi F, Washio M, Tamakoshi A: Site-specific cancer risk due to diabetes mellitus history: evidence from the Japan Collaborative Cohort (JACC) Study. Asian Pac J Cancer Prev 2006, 7:253-259.

3. Rosenberg DJ, Neugut Al, Ahsan H, Shea S: Diabetes mellitus and the risk of prostate cancer. Cancer Invest 2002, 20:157-165.

4. Gonzalez-Perez A, Garcia Rodriguez LA: Prostate cancer risk among men with diabetes mellitus (Spain). Cancer Causes Control 2005, 16:1055-1058.

5. Rodriguez C, Patel AV, Mondul AM, Jacobs EJ, Thun MJ, Calle EE: Diabetes and risk of prostate cancer in a prospective cohort of US men. Am J Epidemiol 2005, I6 I: |47-152.

6. Cheng AY, Fantus IG: Oral antihyperglycemic therapy for type 2 diabetes mellitus. Can Med Assoc ] 2005, I 72:2 I 3-226.

7. Savkur RS, Miller AR: Investigational PPAR-gamma agonists for the treatment of Type 2 diabetes. Expert Opin Investig Drugs 2006, I 5:763-778.
8. Todd MK, Watt MJ, Le J, Hevener AL, Turcotte LP: Thiazolidinediones enhance skeletal muscle triacylglycerol synthesis while protecting against fatty acid-induced inflammation and insulin resistance. Am J Physiol Endocrinol Metab 2007, 292:E485-493.

9. Wilding J: Thiazolidinediones, insulin resistance and obesity: finding a balance. Int J Clin Pract 2006, 60: I272-I280.

10. Boden $G$, Zhang $M$ : Recent findings concerning thiazolidinediones in the treatment of diabetes. Expert Opin Investig Drugs 2006, I 5:243-250.

II. Nunez M, Martin G, Cocca C, Mohamad N, Gutierrez A, Cricco G, Medina V, Rivera E, Croci M, Crescenti E, et al.: Effect of rosiglitazone on N-nitroso-N-methylurea-induced mammary tumors in rat. Anticancer Res 2006, 26:2113-2122.

12. Russu WA: Thiazolidinedione anti-cancer activity: is inhibition of microtubule assembly implicated? Med Hypotheses 2007, 68:343-346.

13. Chang AJ, Song DH, Wolfe MM: Attenuation of peroxisome proliferator-activated receptor gamma (PPARgamma) mediates gastrin-stimulated colorectal cancer cell proliferation. J Biol Chem 2006, 281:|4700-|47|0.

14. Grommes C, Landreth GE, Sastre M, Beck M, Feinstein DL, Jacobs $\mathrm{AH}$, Schlegel $U$, Heneka MT: Inhibition of in vivo glioma growth and invasion by peroxisome proliferator-activated receptor gamma agonist treatment. Mol Pharmacol 2006, 70:I524-I533.

15. Han S, Roman J: Rosiglitazone suppresses human lung carcinoma cell growth through PPARgamma-dependent and PPARgamma-independent signal pathways. Mol Cancer Ther 2006, 5:430-437.

16. Li MY, Lee TW, Yim AP, Chen GG: Function of PPARgamma and its ligands in lung cancer. Crit Rev Clin Lab Sci 2006, 43: I83-202.

17. Martelli ML, luliano R, Le Pera I, Sama I, Monaco C, Cammarota S, Kroll T, Chiariotti L, Santoro M, Fusco A: Inhibitory effects of peroxisome poliferator-activated receptor gamma on thyroid carcinoma cell growth. I Clin Endocrinol Metab 2002, 87:4728-4735.

18. Yu J, Qiao L, Zimmermann L, Ebert MP, Zhang H, Lin W, Rocken C, Malfertheiner P, Farrell GC: Troglitazone inhibits tumor growth in hepatocellular carcinoma in vitro and in vivo. Hepatology 2006, 43:134-143.

19. Saez E, Tontonoz P, Nelson MC, Alvarez JG, Ming UT, Baird SM, Thomazy VA, Evans RM: Activators of the nuclear receptor PPARgamma enhance colon polyp formation. Nat Med 1998 , 4: $1058-106 \mid$

20. Seargent JM, Yates EA, Gill JH: GW a potent antagonist of PPARgamma, inhibits growth of breast tumour cells and promotes the anticancer effects of the PPARgamma agonist rosiglitazone, independently of PPARgamma activation. $\mathrm{Br}$ J Pharmacol 9662, I 43:933-937.

21. Govindarajan R, Ratnasinghe L, Simmons DL, Siegel ER, Midathada MV, Kim L, Kim PJ, Owens RJ, Lang NP: Thiazolidinediones and the risk of lung, prostate, and colon cancer in patients with diabetes. J Clin Oncol 2007, 25:|476-|48I.

22. MacLean CD, Littenberg B, Gagnon M, Reardon M, Turner PD, Jordan C: The Vermont Diabetes Information System (VDIS): study design and subject recruitment for a cluster randomized trial of a decision support system in a regional sample of primary care practices. Clin Trials 2004, I:532-544.

23. Gill SC, Butterworth P, Rodgers B, Mackinnon A: Validity of the mental health component scale of the I2-item Short-Form Health Survey (MCS-12) as measure of common mental disorders in the general population. Psychiatry Res 2007 in press.

24. Sangha O, Stucki G, Liang MH, Fossel AH, Katz JN: The Self-Administered Comorbidity Questionnaire: a new method to assess comorbidity for clinical and health services research. Arthritis Rheum 2003, 49:156-163.

25. Tamborlane WV, Kollman C, Steffes MW, Ruedy KJ, Dongyuan X, Beck RW, Chase P, Fox LA, Wilson DM, Tsalikian E: Comparison of fingerstick hemoglobin A Ic levels assayed by DCA 2000 with the DCCT/EDIC central laboratory assay: results of a Diabetes Research in Children Network (DirecNet) Study. Pediatr Diabetes 2005, 6:13-16.

26. MacLean CD, Littenberg B, Kennedy AG: Limitations of diabetes pharmacotherapy: results from the Vermont Diabetes Information System study. BMC Fam Pract 2006, 7:50.

27. Berria R, Gastaldelli A, Lucidi S, Belfort R, De Filippis E, Easton C, Brytzki R, Cusi K, Jovanovic L, DeFronzo R: Reduction in hemat- 
ocrit level after pioglitazone treatment is correlated with decreased plasma free testosterone level, not hemodilution, in women with polycystic ovary syndrome. Clin Pharmacol Ther 2006,

80: $105-114$.

28. latrakis G, Zervoudis S, Saviolakis A, Troulos M, Antoniou E, Sarantaki A, Lykeridou K, Kourounis G: Women younger than $\mathbf{5 0}$ years with endometrial cancer. Eur J Gynaecol Oncol 2006, 27:399-400.

29. Semple RK, Chatterjee VK, O'Rahilly S: PPAR gamma and human metabolic disease. J Clin Invest 2006, I | 6:58I-589.

30. Lambert MT, Terrell JE, Copeland LA, Ronis DL, Duffy SA: Cigarettes, alcohol, and depression: characterizing head and neck cancer survivors in two systems of care. Nicotine Tob Res 2005, 7:233-241.

31. Ozlu T, Bulbul Y: Smoking and lung cancer. Tuberk Toraks 2005, 53:200-209.

32. Parimon T, Chien JW, Bryson CL, McDonell MB, Udris EM, Au DH: Inhaled corticosteroids and risk of lung cancer among patients with chronic obstructive pulmonary disease. Am J Respir Crit Care Med 2007, I75:7। 2-7I9.

33. Caumes JL, Nousbaum JB, Bessaguet C, Faycal J, Robaszkiewicz M, Gouerou H: Epidemiology of hepatocellular carcinoma in Finistere Prospective study from June 2002 to May 2003. Gastroenterol Clin Biol 2007, 31:259-264.

34. Fukuen S, Iwaki M, Yasui A, Makishima M, Matsuda M, Shimomura I: Sulfonylurea agents exhibit peroxisome proliferator-activated receptor gamma agonistic activity. J Biol Chem 2005, 280:23653-23659.

\section{Pre-publication history}

The pre-publication history for this paper can be accessed here:

http://www.biomedcentral.com/1741-7015/5/17/prepub

Publish with Bio Med Central and every scientist can read your work free of charge

"BioMed Central will be the most significant development for disseminating the results of biomedical research in our lifetime. "

Sir Paul Nurse, Cancer Research UK

Your research papers will be:

- available free of charge to the entire biomedical community

- peer reviewed and published immediately upon acceptance

- cited in PubMed and archived on PubMed Central

- yours - you keep the copyright

Submit your manuscript here:

http://www.biomedcentral.com/info/publishing_adv.asp 